\title{
Polymorphism in secondary squaramides: on the importance of $\pi$-interactions involving the four membered ring $\dagger$
}

(1)

(1)

(1)

(1)

\footnotetext{
Rafel Prohens, ${ }^{*}$ Anna Portell, ${ }^{\mathrm{a}}$ Oriol Vallcorba, ${ }^{\mathrm{b}}$ Mercè Font-Bardia, ${ }^{\mathrm{c}}$ Antonio Bauzá ${ }^{\mathrm{d}}$ and Antonio Frontera ${ }^{*} \mathrm{~d}$
}

a Unitat de Polimorfisme i Calorimetria, Centres Científics i Tecnològics, Universitat de Barcelona, Baldiri Reixac 10, 08028 Barcelona, Spain. E-mail: rafel@ccit.ub.edu

b ALBA Synchrotron Light Source, Cerdanyola del Vallès, Barcelona 08920, Spain

c Unitat de Difracció de Raigs X, Centres Científics i Tecnològics, Universitat de Barcelona, Spain

d Departament de Química, Universitat de les Illes Balears, Crta. de Valldemossa km 7.5, 07122 Palma

(Baleares), Spain. E-mail: toni.frontera@uib.es 
44 ABSTRACT:

45

46 We report the X-ray solid state structures of four new squaric acid derivatives, i.e. three polymorphs of 47 3,4-bisIJ(2-(dimethylamino)ethyl)amino)cyclobut-3-ene-1,2-dione (1a-c) and a co-crystal of compound 481 and resorcinol (2). All structures form interesting supramolecular assemblies in the solid state which 49 have been analyzed using high level DFT calculations and molecular electrostatic potential (MEP) 50 surface calculations. A combination of $\mathrm{H}$-bonding and $\pi-\pi$ stacking interactions of the cyclobutenedione 51 rings are crucial for the formation of the supramolecular assemblies in the solid state. Moreover, unusual 52 antiparallel CO $\cdots \mathrm{CO}$ interactions observed in the X-ray structure of one of the polymorphs of 1 and the $531 \mathrm{p}-\pi$ interactions between one oxygen atom of resorcinol and the squaramide ring in 2 have been 54 characterized using Bader's theory of "atoms-in-molecules" (AIM).

55

56

57

58

59 


\section{INTRODUCTION}

62 Squaric acid amides (squaramides) are highly functionalized four-membered ring systems widely used

63 in molecular recognition and supramolecular chemistry due to their strong ability to establish H-bonding

64 interactions both as donors and acceptors. The enhanced ability of squaramides to establish hydrogen

65 bonding compared to urea/amides has been rationalized considering the increase in the aromaticity of

66 the fourmembered ring upon the formation of H-bonds. 1 In recent years, the use of squaramides in fields

67 related to molecular recognition and catalysis has grown very fast.2-4 For instance, an alkaloid-based

68 bifunctional squaramide has been used as an effective and enantioselective organocatalyst.5 More

69 remarkably,DNA-grafted squaramide bola-amphiphiles have been used in a multicomponent

70 supramolecular polymer system, which can be addressed by DNA-labeled gold nanoparticles through

71 sequence complementarity.6 Moreover, it has been reported that squaramide-based ion transporters

72 enhance the transport of chloride anions in liposomal models and promote sodium chloride influx into

73 the cytosol.7 More importantly, the transport activity of the squaramides correlates with cell death

74 activity attributed to caspase-dependent apoptosis.

75 Squaramides and squaramide monoesters are also used as supramolecular synthons for generating

76 interesting assemblies in the solid state.8 Actually, the utilization of squarate and squarate salts is

77 common in crystal engineering9 and organic material research.10 They have been used by us to analyse

78 the electrostatic compression phenomenon,11a which provides an explanation to the face-to-face $\pi$ -

79 stacked assemblies observed in a series of zwitterionic squaric acid/squaramide compounds.11b

80 Moreover, we have applied the electrostatic compression phenomenon in the crystal engineering field,

81 where we have combined $\pi$-stacking interactions of tertiary $\mathrm{N}$-alkylsquaramides with hydrophobic

82 interactions to construct supramolecular assemblies resembling lipid bilayers. 12

83 In this manuscript, we have synthesized and X-ray characterized three polymorphs of N,N'-bisIJ2-

84 (dimethylamino)ethyl)-squaramide (1) (see Fig. 1a) and a co-crystal of 1 with resorcinol (2) with the

85 additional purpose of extending the knowledge regarding the forces that govern their crystal packing

86 focusing on the differences of polymorphs $1 \mathrm{a}-\mathrm{c}$. To achieve this objective, we combine crystal structure

87 determination and computational analyses of these four squaric acid derivatives. In particular, we focus

88 our attention on analysis of the $\pi$-stacking and lone pair (lp) $-\pi$ interactions involving the four membered

89 ring. 


\section{EXPERIMENTAL AND THEORETICAL METHODS}

\subsection{Materials and measurements}

All chemicals used were of reagent grade and used as received from Sigma-Aldrich.

\subsection{Synthesis of 1}

Synthesis of 1 was carried out following a reported methodology. 13 N,N-Dimethylethylenediamine $(3.09 \mathrm{~mL}, 28.29 \mathrm{mmol})$ was added to a solution of diethylsquarate $(1.60 \mathrm{~g}, 9.43 \mathrm{mmol})$ in absolute ethanol $(66 \mathrm{~mL})$ at r.t. under vigorous stirring and an argon atmosphere. After 24 hours, the resulting white solid was filtered and washed with cold absolute ethanol $(2 \times 10 \mathrm{~mL})$. The solid was dried under vacuum to yield 84\% (2.01 g). 1H-NMR (DMSO-d6, $400 \mathrm{MHz}) \delta: 7.45(\mathrm{~s}, 2 \mathrm{H}) ; 3.59(\mathrm{~m}, \mathrm{~J}=4 \mathrm{~Hz}, 4 \mathrm{H})$; $2.37(\mathrm{t}, \mathrm{J}=4 \mathrm{~Hz}, 4 \mathrm{H}) ; 2.15$ (s, 6H) ppm. 13C-NMR (DMSO-d6, $100 \mathrm{MHz}) \delta: 184.2,169.7,58.5,43.1$, $38.4 \mathrm{ppm}$. MS (ESI) m/z (\%): $255.3(\mathrm{M}+\mathrm{H}+, 100)$.

\subsection{X-ray crystallographic analysis}

Single crystal X-ray diffraction (SXRD) intensity data of solid form 1a were collected using a MAR345 diffractometer with an image plate detector, equipped with graphite monochromated MoKa radiation $(\lambda$ $=0.71073 \AA$ ), and for form $1 \mathrm{~b}$ data were collected using a D8 Venture system equipped with a multilayer monochromator and a Mo microfocus source $(\lambda=0.71073 \AA)$. Frames were integrated with the Bruker SAINT software package using a SAINT algorithm. Data were corrected for absorption effects using the multi-scan method (SADABS).14 The structures were solved and refined using the Bruker SHELXTL software package, a computer program for automatic solution of crystal structures, and refined by the full-matrix leastsquares method with ShelXle Version 4.8.0, a Qt graphical user interface for the SHELXL computer program.15

Powder X-ray diffraction (PXRD) data of 1c and 2 were obtained at 333 and $293 \mathrm{~K}$, respectively, using a PANalytical X'Pert PRO MPD diffractometer in transmission configuration using $\mathrm{Cu} \mathrm{K \alpha} 1+2$ radiation $(\lambda=1.5406 \AA)$ with a focalizing elliptic mirror and a PIXcel detector working at a maximum detector's active length of $3.347^{\circ}$. Capillary geometry has been used with samples placed in glass capillaries (Lindemann) of 0.5 millimetres in diameter measuring from 2 to $70^{\circ}$ in $2 \theta$, with a step size of $0.013^{\circ}$. The powder pattern was indexed using DICVOL04 (ref. 16) and the systematic absences were consistent with a $\mathrm{C} 2 / \mathrm{c}$ space group for $1 \mathrm{c}$ and $\mathrm{P} 42 / \mathrm{n}$ for 2 . The crystal structures were solved by the directspace methodology implemented in TALP17a (for 1c) and FOX17b (for 2) introducing as soft restraints the bond distances and angles obtained from the single-crystal structure of the polymorph 1a. The refinement of the structures has been performed by the Rietveld method using RIBOLS18 and FullProf19 programs. A summary of the crystal data and relevant refinement parameters is given in Table 1.

\subsection{Theoretical methods}

The geometries of the complexes included in this study were computed at the M06-2X/def2-TZVP level of theory using the crystallographic coordinates within the TURBOMOLE program. 20 This level of theory is adequate for studying noncovalent interactions dominated by dispersion effects like $\pi$-stacking. The basis set superposition error for the calculation of interaction energies has been corrected using the counterpoise method.21 The interaction energy $(\Delta \mathrm{E})$ has been computed by subtracting the energy of the monomers (isolated molecules) from the energy of the complex $(\Delta \mathrm{E}=\mathrm{EAB}-\mathrm{EA}-\mathrm{EB})$. The "atoms-inmolecules" (AIM)22 analysis of the electron density has been performed at the same level of theory using the AIMAll program.23

In this manuscript we have used a simple approach to estimate the strength of the noncovalent interactions that play important roles in the crystal packing of compounds $1 \mathrm{a}-\mathrm{c}$ and 2 . That is, we have selected several dimers from the solid state crystal structures and evaluated the binding energies as the difference between the energy of the supermolecule and the sum of the monomers. 


\section{RESULTS AND DISCUSSION}

\subsection{Solid form screening of disquaramide 1}

An intensive polymorph screening using a broad set of thermodynamic and kinetic crystallization conditions from a variety of solvents resulted in three polymorphs (forms 1a, 1b, 1c) obtained in pure forms and a fourth polymorph (1d) obtained as a mixture with an unknown form (Fig. 2). Form $1 \mathrm{~d}$ was obtained directly from synthesis and other crystallizations with different solvents. Some efforts to index its diffractogram were unsuccessful, probably due to either contamination with an unknown phase $(\alpha)$ or a poor resolution diffractogram. Although further efforts to purify the sample by recrystallization were done, no success was achieved and no identification of this unknown phase could be done.

Form $1 \mathrm{~b}$ was obtained pure from a cocrystallization experiment of 1 with glutamic acid, in particular, recrystallization in ethanol. Apart from studying the polymorphism of squaramides, in this work, special attention has been given to designing cocrystals and analyzing their supramolecular synthons using squaramides as scaffolds. Several cases of new polymorphs obtained by induced crystallization with additives or using cocrystals as key intermediates are reported in the literature. 24 Other attempts at cocrystallization of 1 with urea and nicotinamide in ethanol at r.t. through the reaction crystallization technique have resulted in form $1 \mathrm{~b}$ impurified by the coformer.

Form 1a could only be obtained from slow cooling recrystallization in acetonitrile as yellowish needles suitable for SXRD analysis. Finally, form 1c has been only detected by DSC analysis from a solid-solid transition of forms $1 \mathrm{~d}(+\alpha)$ and $1 \mathrm{~b}$.

DSC analysis of form $1 \mathrm{~d}(+\alpha$, which is hypothesized) shows an endothermic transition to form 1c (m.p. $=227{ }^{\circ} \mathrm{C}$ ) on heating (confirmed by variable temperature PXRD analysis, starting at about $45^{\circ} \mathrm{C}$ with an enthalpy of $4 \mathrm{~J} \mathrm{~g}-1$. When a cooling-heating DSC analysis is performed, the transition appears at the same temperature with a lower enthalpy $(1.5 \mathrm{~J} \mathrm{~g}-1)$, which suggests the possibility of an incomplete reversible transition (Fig. 4). Form $1 \mathrm{~b}$ presents an endothermic solid-solid phase transition into form 1c, at $150{ }^{\circ} \mathrm{C}$ with an enthalpy of $20 \mathrm{~J} \mathrm{~g}-1$, confirmed by variable temperature PXRD analysis. The DSC analysis of form 1a shows a solid-solid transition at $44{ }^{\circ} \mathrm{C}$ with an enthalpy of $3 \mathrm{~J} \mathrm{~g}-1$ (Fig. 3). Calorimetric data for the crystal forms of compound 1 are summarized in Table 2.

In terms of the thermodynamic relationship of this polymorphic system, form $1 \mathrm{~d}(+\alpha)$ can be considered enantiotropically related to form 1c. Solid samples of form 1a kept at r.t. tend to transform irreversibly into form $1 \mathrm{~d}(+\alpha)$, see the ESI. $\uparrow$ Form $1 \mathrm{~b}$ is enantiotropically related to form $1 \mathrm{c}$, since an endothermic solid-solid transition is observed by DSC. A scheme of the polymorph transformations among the different forms is shown in Fig. 5.

The crystal structures of forms $1 \mathrm{a}$ and $1 \mathrm{~b}$ were determined by SXRD using the needles grown by slow evaporation of an acetonitrile solution of 1 at room temperature. The crystal structure of $1 \mathrm{c}$ was solved by means of direct space strategies from variable temperature PXRD analysis starting from form $1 \mathrm{~d}(+\alpha)$ or form $1 \mathrm{~b}$. The crystal structure of form $1 \mathrm{~d}$ could not be solved. Crystal data are shown in Table 1. A cocrystal screening of 1 was also performed. A total number of 162 experiments using selected combinations between 36 solvents and 9 coformers (fumaric, p-nitrobenzoic, glutaric, glutamic, oxalic, and citric acids, resorcinol, urea and nicotinamide) have been conducted, distributed mainly in two methodologies (drop grinding and reaction crystallization techniques) to test the formation of cocrystals with 1. Evidence of cocrystallization was detected by measuring the XRPD diffractograms and DSC thermograms for each solid obtained during the screen. New cocrystals were obtained with fumaric acid (which is the subject of another work25) and resorcinol. Suitable crystals of cocrystal 1/resorcinol for SXRD analysis were obtained in acetonitrile.

\subsection{Theoretical study of polymorphs 1a-c}

In Fig. 6 we show the DFT-optimized geometries of polymorphs 1a-c along with their relative energies. We hav started from the X-ray coordinates and have performed geometry optimization. Remarkably, we have found three local minima that correspond to the three polymorphs. The energy difference between them is small and the most stable one corresponds to 1a that is approximately $1 \mathrm{kcal} \mathrm{mol}-1$ more stable than the other two ( $1 \mathrm{~b}$ and $1 \mathrm{c}$ ) which are almost isoenergetic.

The difference between the polymorphs is the relative orientation of both (dimethylamino)ethyl arms. In 1a both arms are disposed perpendicular to the squaramide ring plane and pointing to opposite 
directions. In $1 \mathrm{c}$ both arms are disposed in a more coplanar manner and in $1 \mathrm{~b}$ (Fig. 6b) one arm is disposed perpendicularly and the other one in a coplanar manner with respect to the squaramide ring. Interestingly, the orientation of the arms has a strong influence on the solid state architecture of this compound and also the formation of supramolecular assemblies. That is, in 1a the orientation of the arms does not allow the squaramide ring to establish $\pi$-stacking interactions, as presented in Fig. 6a (right). Curiously, in $1 \mathrm{~b}$ the presence of only one arm perpendicular to the ring allows the formation of discrete $\pi$-stacked selfassembled dimers. Finally, in polymorph $1 \mathrm{c}$, the absence of perpendicular arms facilitates the formation of infinite 1D ladders dominated by $\pi$-stacking interactions (see Fig. $6 \mathrm{c}$ ). All polymorphs exhibit the H-bonding pattern typical for secondary squaramides (infinite chains of squaramides connected by double $\mathrm{C} \checkmark \mathrm{O} \cdots \mathrm{H}-\mathrm{N}$ H-bonds, see Fig. 7) with distances close to $2 \AA$. In Fig. 8 we have presented the molecular electrostatic potential (MEP) of 1a. It can be observed that the MEP value at the NH groups is $+52 \mathrm{kcal} \mathrm{mol}-1$ and the same value but of opposite sign is obtained at the $\mathrm{O}$ atoms of the squaramide. Therefore, the formation of the $\mathrm{C} \checkmark \mathrm{O} \cdots \mathrm{H}-\mathrm{N}$ is electrostatically very favored. The MEP surface also reveals that the MEP value at the $\mathrm{sp} 3 \mathrm{~N}$ atom $(-33 \mathrm{kcal} \mathrm{mol}-1)$ is significantly smaller (in absolute value) than that at the $\mathrm{O}$ atom. Therefore, the ability of the $\mathrm{N}$ atom to form $\mathrm{H}$-bonds is much lower than the carbonyl $\mathrm{O}$ atoms.

In Fig. 9 we show partial views of the solid state structures of the polymorphs 1a-c. The main difference among them is the behavior of the four membered ring. That is, in 1a the squaramide ring does not participate in $\pi$-stacking interactions; instead hydrophobic interactions between the arms are established. We have computed the interaction energy of a single interaction (see Fig. 9a, right), which is weak ( $\Delta \mathrm{E} 1$ $=-1.6 \mathrm{kcal} \mathrm{mol}-1)$. Nevertheless, the cooperative formation of multiple interactions along with the higher stability of this polymorph likely explains this experimental observation. In $1 \mathrm{~b}$, self-assembled dimers are formed with a short $\pi-\pi$ distance $(3.23 \AA)$. The interaction energy $(\Delta \mathrm{E} 2=-18.4 \mathrm{kcal} \mathrm{mol}-1)$ is large thus confirming the importance of this interaction in the solid state. In this particular dimer, we have also computed the interaction energy using Grimme's D3 dispersion correction26 in order to know if dispersion effects are important in this $\pi$-stacked system. As a result, the computed interaction energy is slightly more favorable including the dispersion correction $(-19.5 \mathrm{kcal} \mathrm{mol}-1)$. Finally, in $1 \mathrm{c}$ infinite 1D ladders are assembled by the formation of antiparallel CO $\cdots \mathrm{CO}$ interactions. Concerning this type of interaction, Allen et al. have proposed that it can be competitive with hydrogen bonds.27 There are three possible motifs for the carbonyl-carbonyl interactions: slightly sheared antiparallel, perpendicular and sheared parallel. We have computed the interaction energy of the $\mathrm{CO} \cdots \mathrm{CO}$ interaction in $1 \mathrm{c}$ using the model dimer shown in Fig. 9c. It is moderately strong $(\Delta \mathrm{E} 3=-8.6 \mathrm{kcal} \mathrm{mol}-1)$ and comparable to reported values for squaramide derivatives 12 and other carbonyl compounds like uracyl and cytosine derivatives. 28

\subsection{Theoretical study of noncovalent interactions in 2}

Compound 2 is a cocrystal of 1 and resorcinol. In this case the arms are pointing to the same direction, thus facilitating the formation of $\pi$-stacking interactions at the opposite side. The resorcinol molecules interact with the squaramide via a combination of $1 \mathrm{p}-\pi$ and H-bonding interactions. As mentioned previously in the structural description, compound 2 also forms the typical H-bonding pattern of secondary squaramides. Moreover, it also forms interesting supramolecular $1 \mathrm{p}-\pi / \pi-\pi / \pi-1 \mathrm{p}$ assemblies (see Fig. 10a) in the solid state assisted by $\mathrm{OH} \cdots$ NIJMe)2R H-bonding interactions. The interaction energy of the antiparallel $\pi$-stacking complex (see Fig. 10b) is $\Delta \mathrm{E} 4=-14.1 \mathrm{kcal} \mathrm{mol}-1$ which is comparable to those previously reported for squaramide rings 8,12 and considerably stronger than those of $\pi$-stacking complexes in aromatic rings. We have also computed the binding energy of the squaramide with resorcinol which is $-13.1 \mathrm{kcal} \mathrm{mol}-1$. In order to evaluate cooperativity effects between the $\pi$-stacking and the $1 p-\pi$ interaction, we have also computed the interaction energy of the assembly shown in Fig. 10c. This binding energy has been computed considering that the $\pi$-stacked complex has been previously formed and only the interaction with resorcinol is evaluated. As a result, the interaction energy becomes slightly more favorable $(\Delta \mathrm{E} 5=-14.3 \mathrm{kcal} \mathrm{mol}-1)$ thus revealing a modest cooperativity effect between the $\pi-\pi$ and lp $-\pi$ interactions.

Finally, we have used Bader's theory of atoms in molecules 29 to characterize the antiparallel CO $\cdots \mathrm{CO}$ interactions described above for $1 \mathrm{c}$ (see Fig. $9 \mathrm{c}$ ) and the $1 \mathrm{p}-\pi$ interaction in 2 (see Fig. 10c). The existence of a bond $\mathrm{CP}$ and a bond path connecting two atoms is clear evidence of interaction, since it 
indicates that electron density is accumulated between the nuclei that are linked by the associated atomic interaction line.22 In Fig. 11 we present the critical points (CPs) and bond paths for the dimer of polymorph 1c. The distribution of CPs confirms the existence of antiparallel CO $\cdots \mathrm{CO}$ interaction since two bond CPs (red spheres) and bond paths inter-connect the carbon atom of one monomer to the $\mathrm{O}$ atom of the other monomer and vice versa. The interaction is further characterized by ring critical points (yellow spheres) due to the formation of a supramolecular ring. Moreover, the distribution in 1c also reveals the existence of hydrophobic $\mathrm{C}-\mathrm{H} \cdots \mathrm{H}-\mathrm{C}$ interactions between the arms which are characterized by a bond $\mathrm{CP}$ and a bond path connecting two $\mathrm{H}$-atoms of the arms. In Fig. 12 we show the AIM analysis of the complex between resorcinol and the squaramide corresponding to compound 2 . The $\mathrm{OH} \cdots \mathrm{N}$ H-bond interaction is characterized by a bond $\mathrm{CP}$ and a bond path connecting the phenolic $\mathrm{H}$ atom to the $\mathrm{N}$-atom of the tertiary amine group. Remarkably, the $\mathrm{lp}-\pi$ interaction is also confirmed since a bond $\mathrm{CP}$ and a bond path connect the phenolic $\mathrm{O}$ atom to one $\mathrm{C}$ atom of the four membered ring. Therefore, this phenolic group is able to act as a donor and acceptor simultaneously. The distribution also reveals the existence of a $\mathrm{C}-\mathrm{H} \cdots \pi$ interaction (bond path connecting the $\mathrm{C}-\mathrm{H}$ to one $\mathrm{C}$ atom of resorcinol) that is favored due to the existence of two electron donating substituents in the aromatic ring. Finally, the assembly is further stabilized by a $\mathrm{C}-\mathrm{H} \cdots \mathrm{O}$ long hydrogen bond characterized by a bond $\mathrm{CP}$ inter-connecting the $\mathrm{H}$ and $\mathrm{O}$ atoms. 


\section{CONCLUSION}

283 The crystal structures of four new squaric acid derivatives have been determined by single crystal and 284 powder X-ray diffraction. Three of them are polymorphs which present the typical H-bonding pattern 285 for secondary disquaramides. The main difference is the participation of the highly functionalized four 286 membered ring in $\pi$-stacking interactions which depends on the conformation of the dimethylaminoethyl 287 chains. The noncovalent interactions that govern the crystal packing have been analyzed by means of 288 DFT (M06-2X) calculations and AIM theory. The $\pi$-system of the squaric acid derivatives is able to 289 establish a series of $\pi$-interactions, including stacking and $\mathrm{lp}-\pi$ in addition to the expected $\mathrm{H}$-bonding 290 interactions. They have been evaluated energetically and characterized using the distribution of critical 291 points and bond paths. 
293 Conflicts of interest

294

295 The authors declare no competing financial interest.

296

297

298

299 
AB and AF thank DGICYT of Spain (project CTQ2014-57393-C2-1-P, FEDER funds) for funding and 303 the CTI (UIB) for free allocation of computer time.

304 
3071 A. Frontera, P. M. Deyà, D. Quiñonero, C. Garau, P. Ballester and A. Costa, Chem. - Eur. J., 308 2002, 8, 433-438.

(a) D. Enders, U. Kaya, P. Chauhan, D. Hack, K. Deckers, R. Puttreddy and K. Rissanen, Chem. Commun., 2016, 52, 1669-1672; (b) A. S. Kumar, T. P. Reddy, R. Madhavachary and D. B. Ramachary, Org. Biomol. Chem., 2016, 14, 5494-5499; (c) D. Zhou, Z. Huang, X. Yu, X. Y. Wang, J. Li, W. Wang and H. Xie, Org. Lett., 2015, 17, 5554-5557; (d) L. Chen, Z.-J. Wu, M.L. Zhang, D.-F. Yue, X.-M. Zhang, X.-Y. Xu and W.-C. Yuan, J. Org. Chem., 2015, 80, 12668 12675; (e) B. Shan, Y. Liu, R. Shi, S. Jin, L. Li, S. Chen and Q. Shu, RSC Adv., 2015, 5, 96665-96669; ( f ) M.-X. Zhao, H.-K. Zhu, T.-L. Dai and M. Shi, J. Org. Chem., 2015, 80, 11330-11338; (g) J. Peng, B.-L. Zhao and D.-M. Du, Adv. Synth. Catal., 2015, 357, 36393647; (h) W. Sun, L. Hong, G. Zhu, Z. Wang, X. Wei, J. Ni and R. Wang, Org. Lett., 2014, 16, 544; (i) X.-B. Wang, T.-Z. Li, F. Sha and X.-Y. Wu, Eur. J. Org. Chem., 2014, 739; (j) V. Kumar and S. Mukherjee, Chem. Commun., 2013, 49, 11203-11205; (k) K. S. Yang, A. E. Nibbs, Y. E. Turkmen and V. H. Rawal, J. Am. Chem. Soc., 2013, 135, 16050-16053; (1) P. Kasaplar, C. Rodriguez-Escrich and M. A. Pericas, Org. Lett., 2013, 15, 3498-3501; (m) P. Kasaplar, P. Riente, C. Hartmann and M. A. Pericas, Adv. Synth. Catal., 2012, 354, 2905-2910.

(a) R. B. P. Elmes, P. Turner and K. A. Jolliffe, Org. Lett., 2013, 15, 5638-5641; (b) K. Bera and I. N. N. Namboothiri, Chem. Commun., 2013, 49, 10632-10634; (c) C. Jin, M. Zhang, L. Wu, Y. Guan, Y. Pan, J. Jiang, C. Lin and L. Wang, Chem. Commun., 2013, 49, 2025-2027; (d) C. Lopez, E. Sanna, L. Carreras, M. Vega, C. Rotger and A. Costa, Chem. - Eur. J., 2013, 8, 8487; (e) B. Soberats, L. Martinez, E. Sanna, A. Sampedro, C. Rotger and A. Costa, Chem. - Eur. J., 2012, 18, 7533-7542; ( f) V. Amendola, L. Fabbrizzi, L. Mosca and F.-P. Schmidtchen, Chem. - Eur. J., 2011, 17, 5972; (g) S. Tomas, R. Prohens, G. Deslongchamps, P. Ballester and A. Costa, Angew. Chem., Int. Ed., 1999, 38, 2208-2211. Angew. Chem., Int. Ed., 2012, 51, 4426-4430.

Y. Liu, Y. Zhang, H.-X. Duan, D.-Y. Wanyan and Y.-Q. Wang, Org. Biomol. Chem., 2017, 15, 8669-8679.

W. E. M. Noteborn, V. Saez-Talens and R. E. Kieltyka, ChemBioChem, 2017, 18, 1995-1999. 
(a) R. Prohens, A. Portell, M. Font-Bardia, A. Bauzá and A. Frontera, CrystEngComm, 2017, 19, 3071-3077; (b) A. Portell and R. Prohens, Cryst. Growth Des., 2014, 14, 397-400; (c) A. Portell, X. Alcobe, L. M. Lawson Daku, R. Cerny and R. Prohens, Powder Diffr., 2013, 28, S470-S480; (d) R. Prohens, A. Portell and X. Alcobe, Cryst. Growth Des., 2012, 12, 45484553; (e) M. C. Rotger, M. N. Piña, A. Frontera, G. Martorell, P. Ballester, P. M. Deyà and A. Costa, J. Org. Chem., 2004, 69, 2302-2308.

(a) T. Kolev, R. W. Seidel, H. Mayer-Figge, M. Spiteller, W. S. Sheldrick and B. B. Koleva, Spectrochim. Acta, Part A, 2009, 72, 502-509; (b) T. Kolev, H. Mayer-Figge, R. W. Seidel, W. S. Sheldrick, M. Spiteller and B. B. Koleva, J. Mol. Struct., 2009, 919, 246-254; (c) B. Ivanova and M. Spiteller, Spectrochim. Acta, Part A, 2010, 77, 849-855; (d) S. L. Georgopoulos, H. G. M. Edwards and L. F. C. De Oliveira, Spectrochim. Acta, Part A, 2013, 111, 54-61.

(a) C. Qin, Y. Numata, S. Zhang, X. Yang, A. Islam, K. Zhang, H. Chen and L. Han, Adv. Funct. Mater., 2014, 24, 3059-3066; (b) Z. Dega-Szafran, G. Dutkiewicz and Z. Kosturkiewicz, J. Mol. Struct., 2012, 1029, 28-34; (c) P. Barczyński, Z. Dega-Szafran, A. Katrusiak and M. Szafran, J. Mol. Struct., 2012, 1018, 28-34.

(a) A. Portell, M. Font-Bardia and R. Prohens, Cryst. Growth Des., 2013, 13, 4200-4203; (b) R. Prohens, A. Portell, M. Font-Bardia, A. Bauzá and A. Frontera, Cryst. Growth Des., 2014, 14, $2578-2587$.

R. Prohens, A. Portell, M. Font-Bardia, A. Bauzá and A. Frontera, CrystEngComm, 2016, 18, $6437-6443$.

R. Prohens, S. Tomas, J. Morey, P. M. Deya, P. Ballester and A. Costa, Tetrahedron Lett., 1998, 39, 1063-1066.

SADABS Bruker AXS, Madison, Wisconsin, USA, 2004; SAINT, Software Users Guide, Version 6.0, Bruker Analytical X-ray Systems, Madison, WI, 1999; G. M. Sheldrick, SADABS v2.03: Area-Detector Absorption Correction, University of Göttingen, Germany, 1999; Saint Version 7.60A, Bruker AXS, 2008; SADABS V. 2008-1, 2008.

G. M. Sheldrick, Acta Crystallogr., Sect. A: Found. Crystallogr., 2008, 64, 112-122.

A. Boultif and D. Louër, J. Appl. Crystallogr., 2004, 37, 724-731.

(a) O. Vallcorba, J. Rius, C. Frontera and C. Miravitlles, J. Appl. Crystallogr., 2012, 45, 12701277; (b) V. Favre-Nicolin and R. Černý, J. Appl. Crystallogr., 2002, 35, 734-743. 
18 W. A. Dollase, J. Appl. Crystallogr., 1986, 19, 267-272.

37019 J. Rodriguez-Carvajal, Phys. B, 1993, 192, 55-69.

37120 R. Ahlrichs, M. Bär, M. Häser, H. Horn and C. Kölmel, Chem. Phys. Lett., 1989, 162, 165-169.

$37221 \quad$ S. F. Boys and F. Bernardi, Mol. Phys., 1970, 19, 553-566.

37322 R. F. W. Bader, Chem. Rev., 1991, 91, 893-928.

37423 T. A. Keith, AIMAll (Version 13.05.06), TK Gristmill Software, Overland Park KS, USA, 2013.

$37524 \quad$ (a) P. K. Thallapally, R. K. R. Jetti, A. K. Katz, H. L. Carrell, K. Singh, K. Lahiri, S. Kotha, R. 376 Boese and G. R. Desiraju, Angew. Chem., Int. Ed., 2004, 43, 1149-1155; (b) C. Puigjaner, R. 377 Barbas, A. Portell, I. Valverde, X. Vila, X. Alcobe, M. Font-Bardia and R. Prohens, $378 \quad$ CrystEngComm, 2012, 14, 362-365.

37925 R. Prohens, A. Portell, M. Font-Bardia, A. Bauzá and A. Frontera, Chem. Commun., submitted.

38026 S. Grimme, J. Antony, S. Ehrlich and H. Krieg, J. Chem. Phys., 2010, 132, 154104-154119.

38127 F. H. Allen, C. A. Baalham, J. P. M. Lommerse and P. R. Raithby, Acta Crystallogr., Sect. B: $382 \quad$ Struct. Sci., 1998, 54, 320-329.

38328 (a) M. Barceló-Oliver, C. Estarellas, A. Garcia-Raso, A. Terrón, A. Frontera, D. Quiñonero, E. 384 385 386

(a) R. F. W. Bader, J. Phys. Chem. A, 1998, 102, 7314-7323. 
Figure. 1. (a) Squaric acid derivatives $1 \mathrm{a}-1 \mathrm{c}$ and 2 studied in this work. (b) H-bonding pattern typical for secondary disquaramides.

393

Figure. 2 PXRD diagrams of the polymorphs of 1.

395

Figure. 3 DSC thermograms of the polymorphs of 1.

Figure. 4 DSC thermogram of form $1 \mathrm{~d}$ showing a reversible transition into form 1c during a heatingcooling experiment.

400

401

Figure. 5 Polymorphic transformations of compound 1.

402

403

404

Figure. 6 Left: M06-2X/def2-TZVP optimized geometries of polymorphs 1a (a), 1b (b) and 1c (c).

405

406

Figure. 7 Partial view of the X-ray solid state structures of polymorphs 1a

407

(a), 1b (b) and 1c (c) showing the H-bonding pattern typical for secondary

408 squaramides. Distances in $\AA$.

409

410

Figure. 8 MEP plotted onto the van der Waals surface (isosurface, 0.002 a.u.) of 1a. MEP values at selected points on the surface are indicated in kcal mol-1.

412

413

Figure. 9 Left: Partial view of the X-ray solid state structures of polymorphs 1a (a), 1b (b) and 1c (c).

414 Right: Interaction energy of a representative dimer of each polymorph. Distances in Å.

415

Figure. 10 (a) X-ray fragment of compound 2. (b and c) Theoretical models used to evaluate the noncovalent interactions. In complex (c) the interaction energy has been computed considering the squaramide $\pi$-stacked dimer as a monomer (only $\mathrm{lp}-\pi$ and $\mathrm{H}$-bond interactions are evaluated). Distances in $\AA$.

420

421 Figure. 11 Distribution of bond and ring critical points (red and yellow spheres, respectively) and bond 422 paths for the dimer of compound 1c. 
424 Figure. 12 Distribution of bond and ring critical points (red and yellow spheres, respectively) and bond 425 paths for the resorcinol-squaramide complex in compound 2.

426

427 
430

(a)<smiles>CN(C)CCNc1c(NCCN(C)C)c(=O)c1=O</smiles>

1a, $1 b, 1 c$<smiles>CN(C)CCNc1c(NCCN(C)C)c(=O)c1=O</smiles>

2 (b)

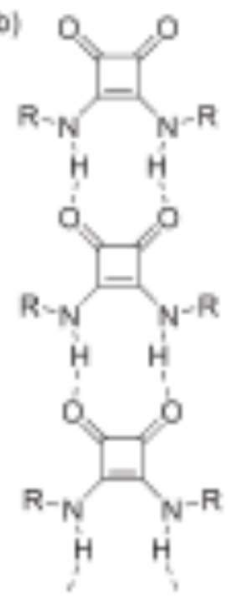




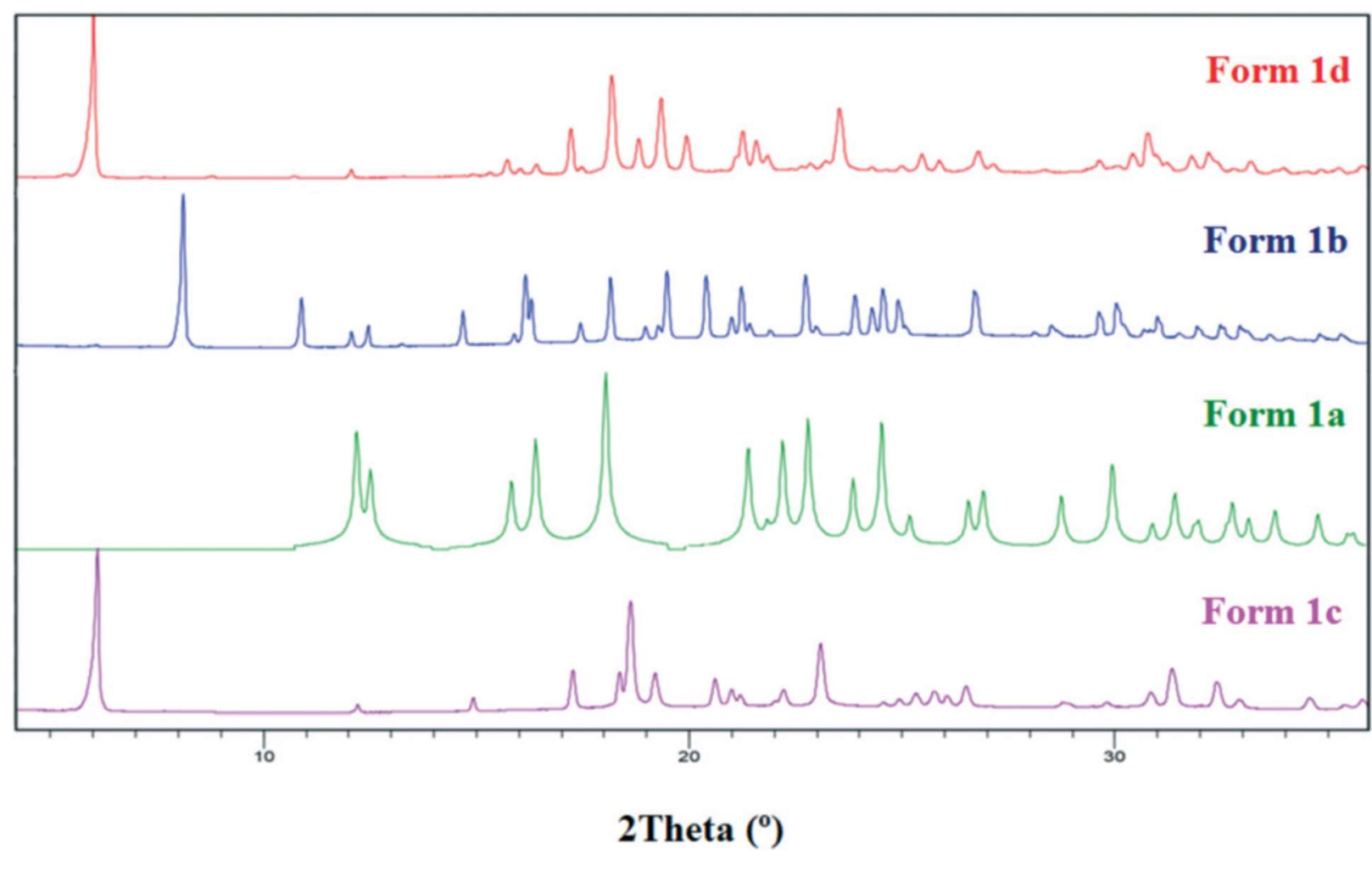




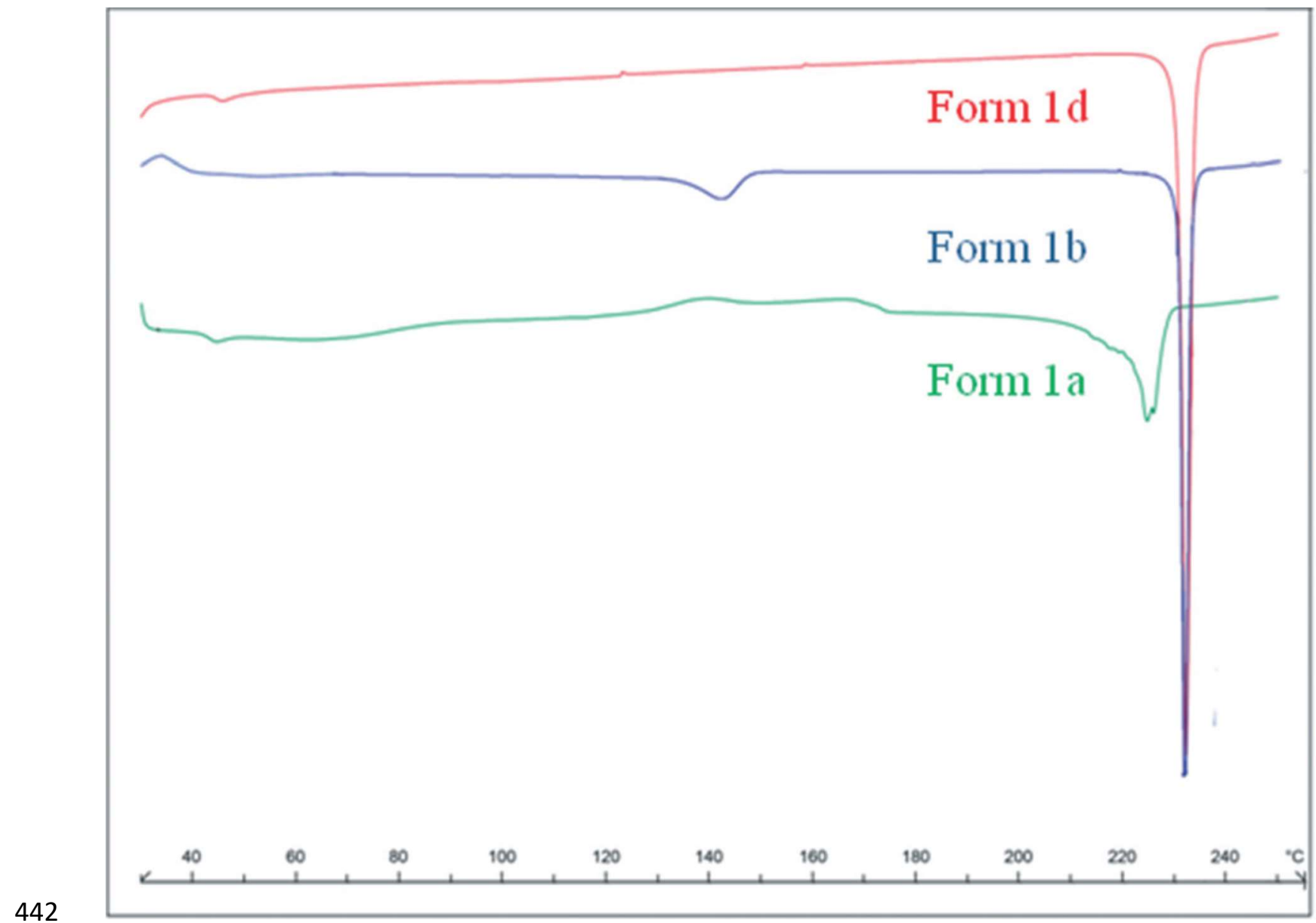


445

446

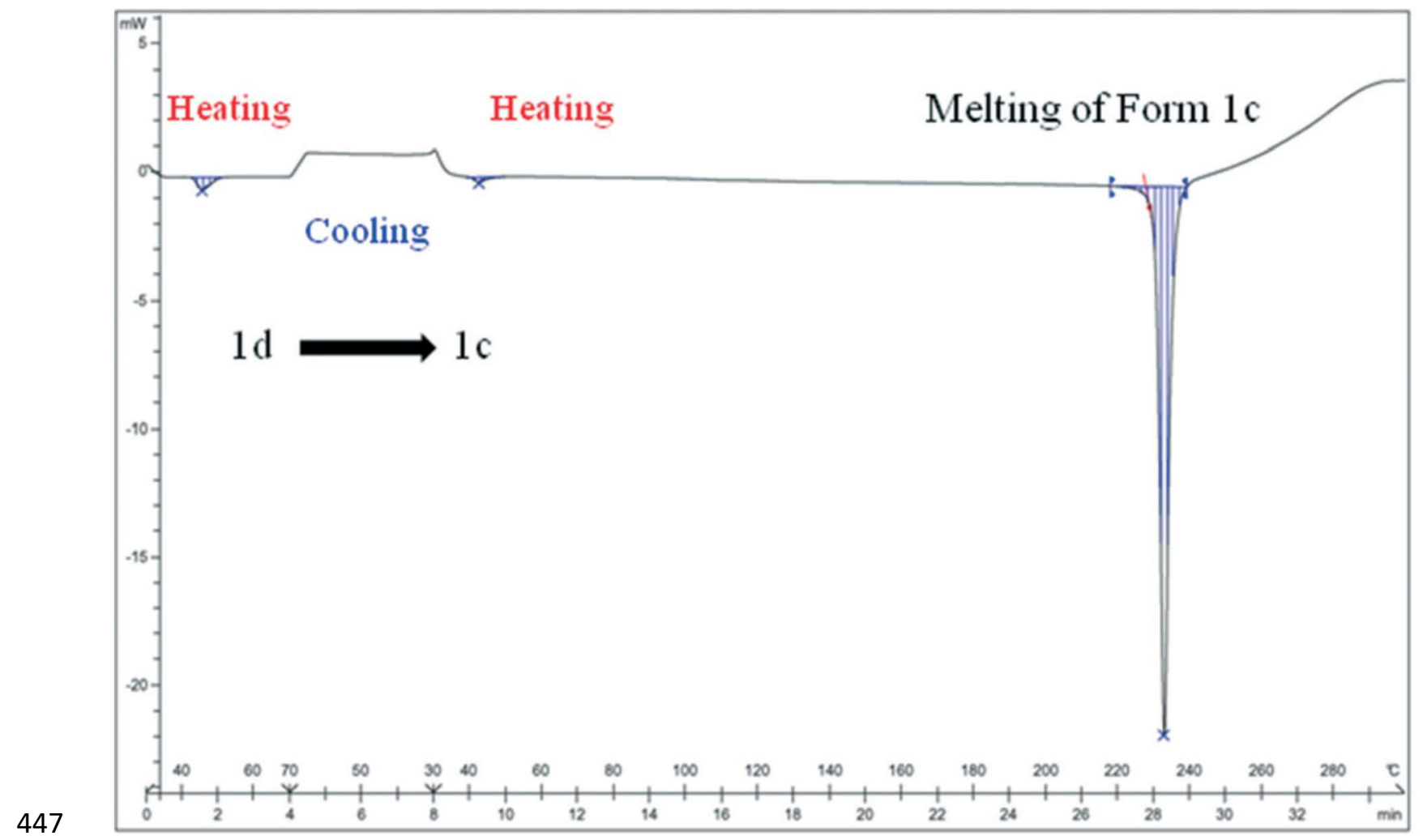

448 


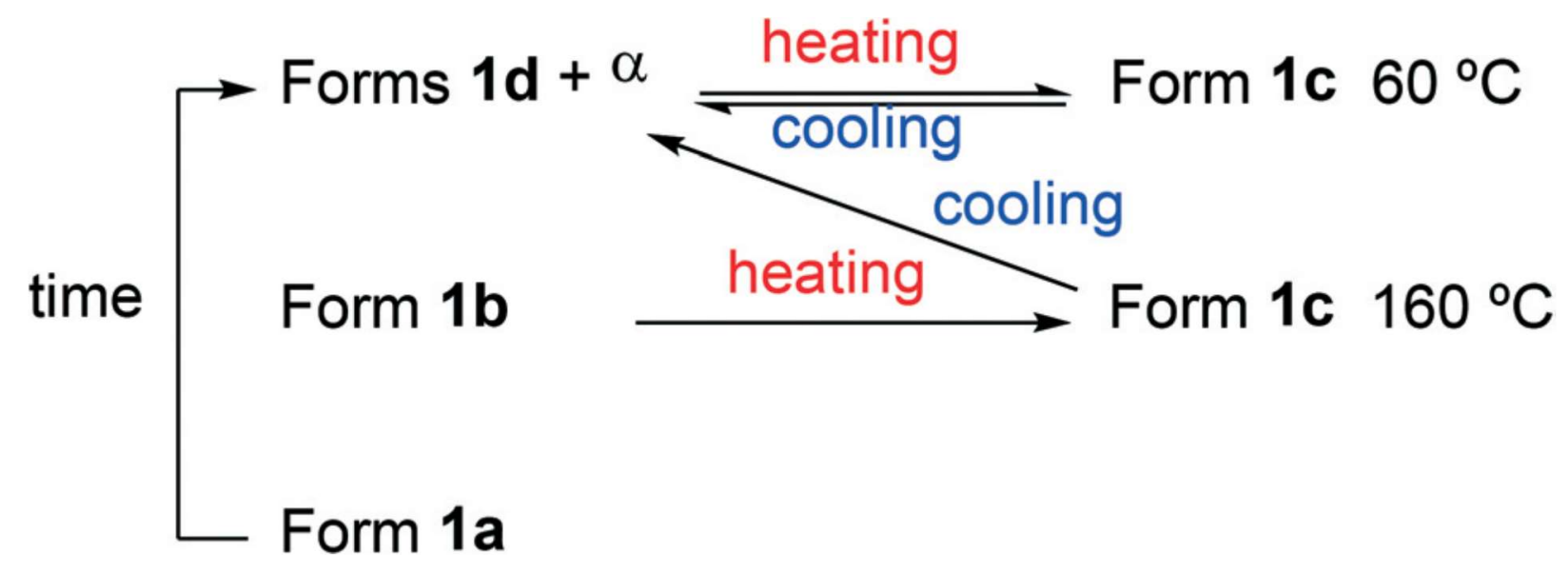

453 


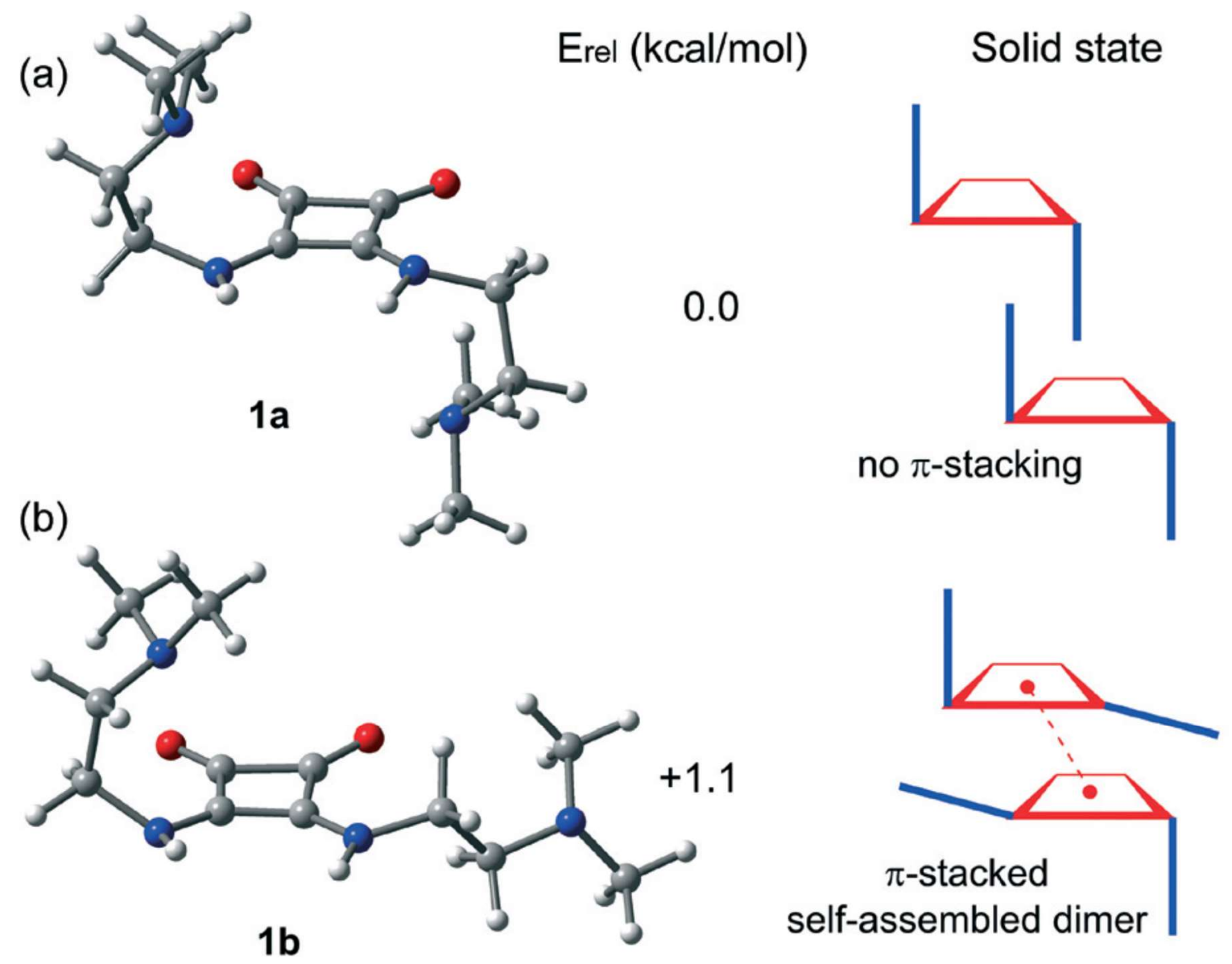

(c)

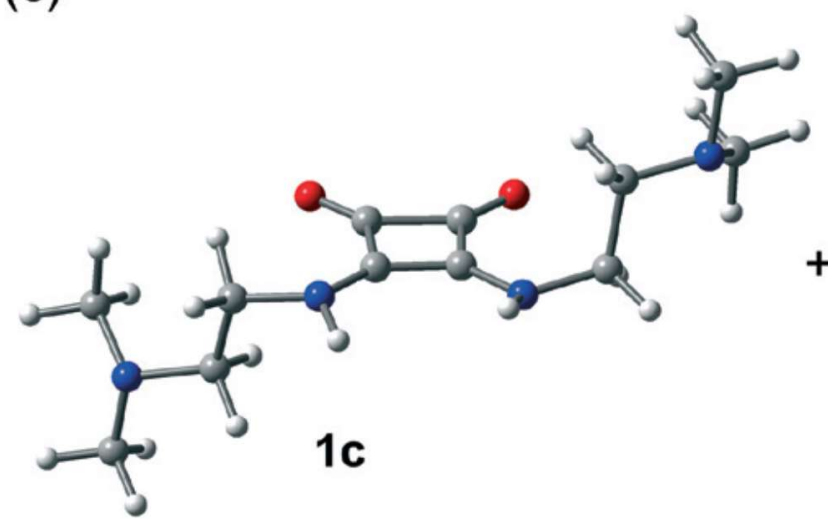

$+1.2$

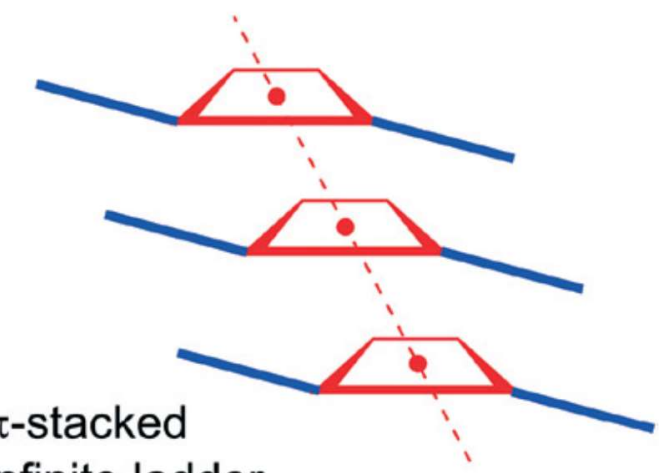

1D infinite ladder 

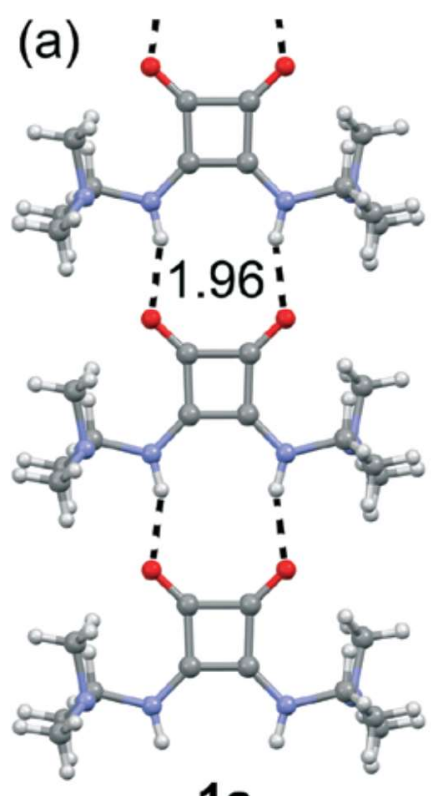

$1 a$ (b)
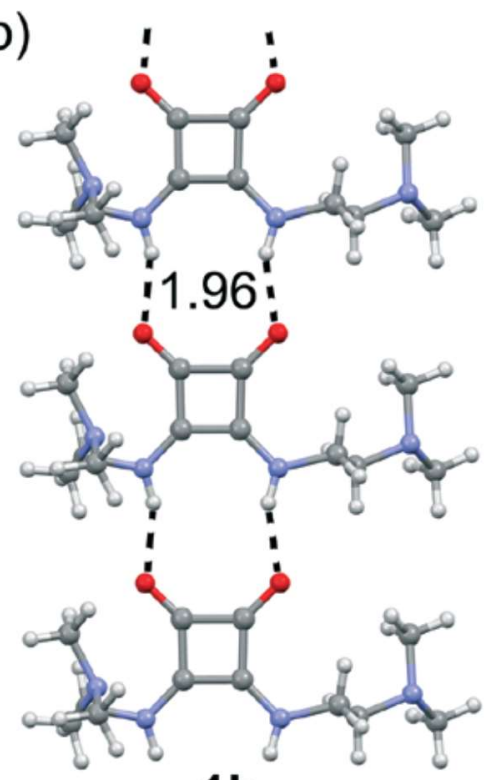

$1 b$

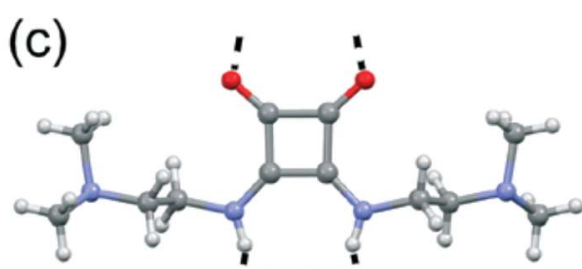

2.00

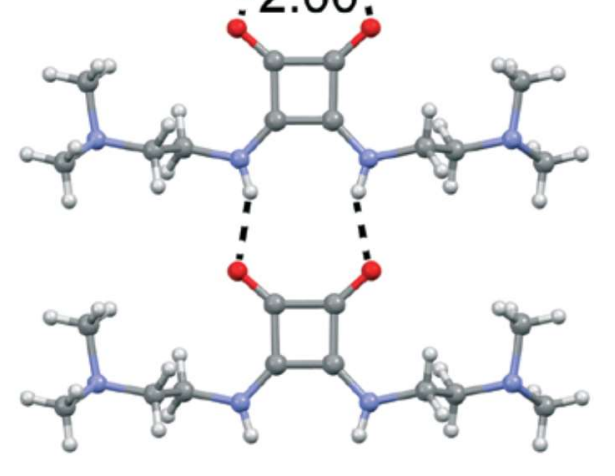

$1 c$ 


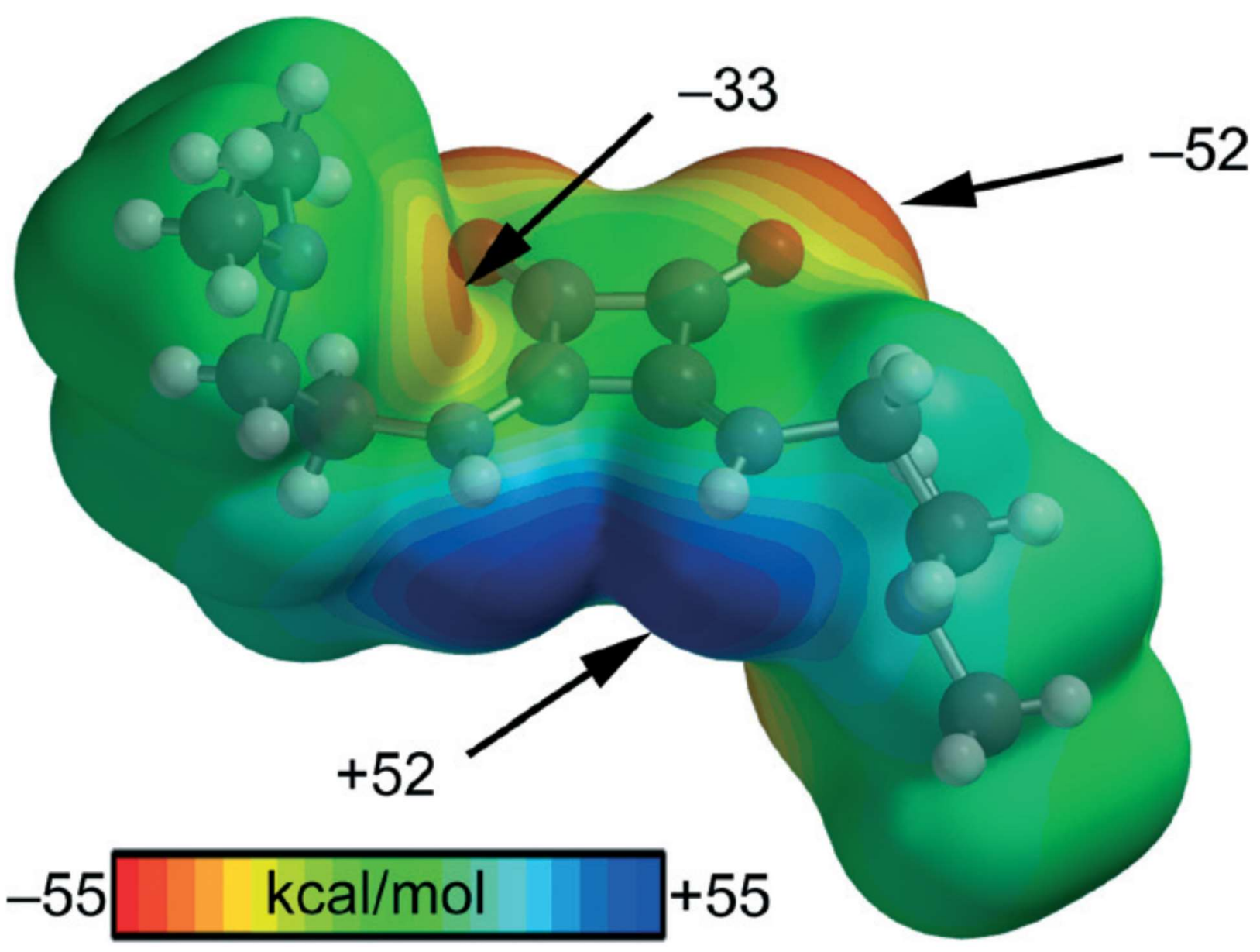

471 

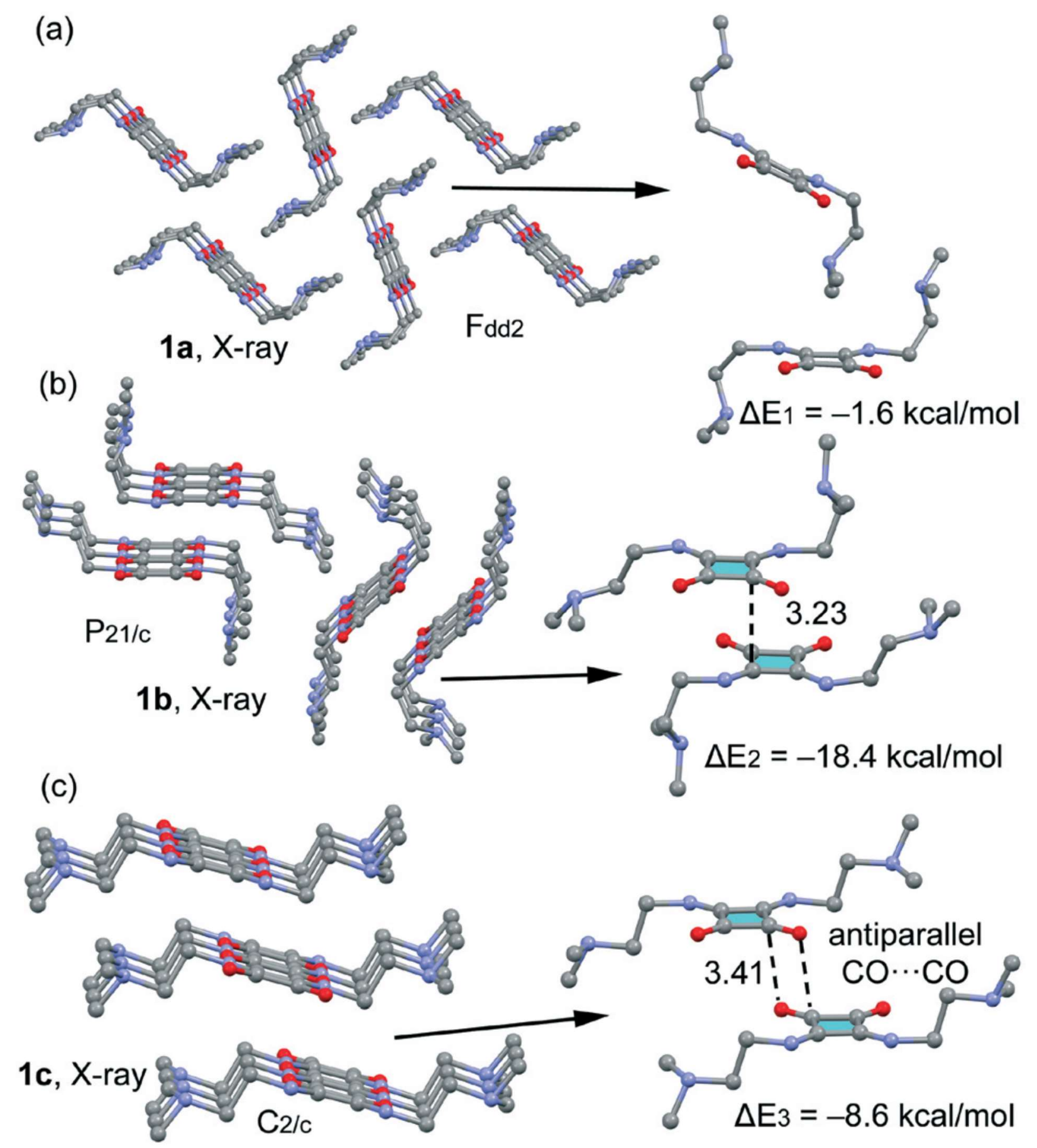


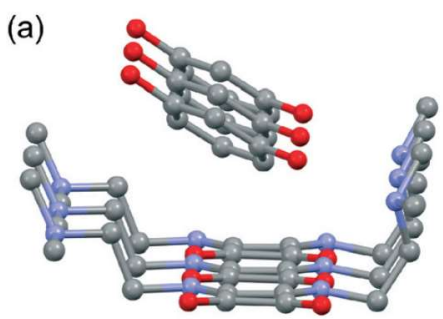

(b)

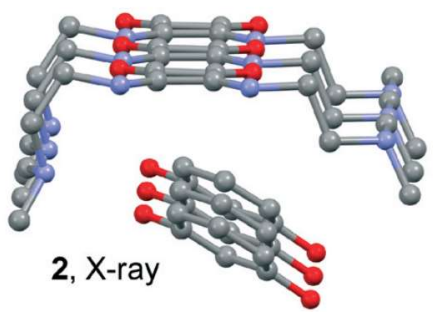

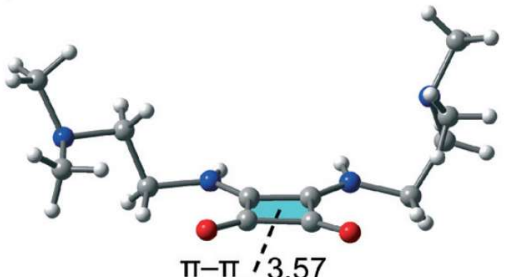

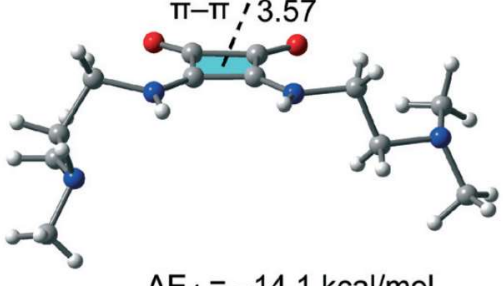

$\Delta \mathrm{E}_{4}=-14.1 \mathrm{kcal} / \mathrm{mol}$
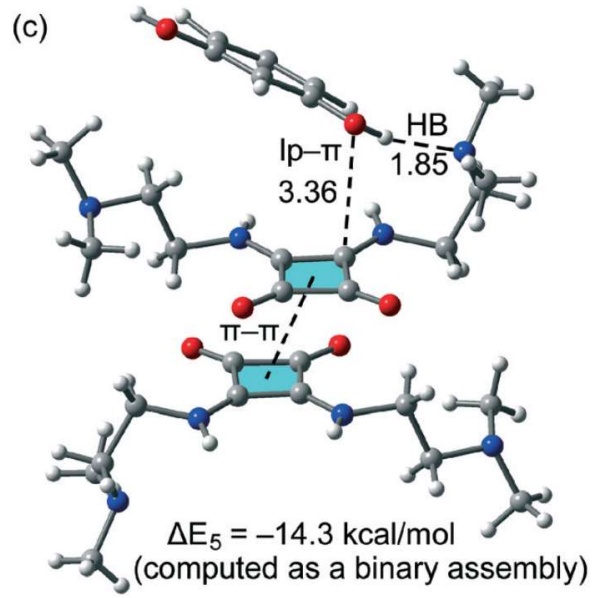

481 


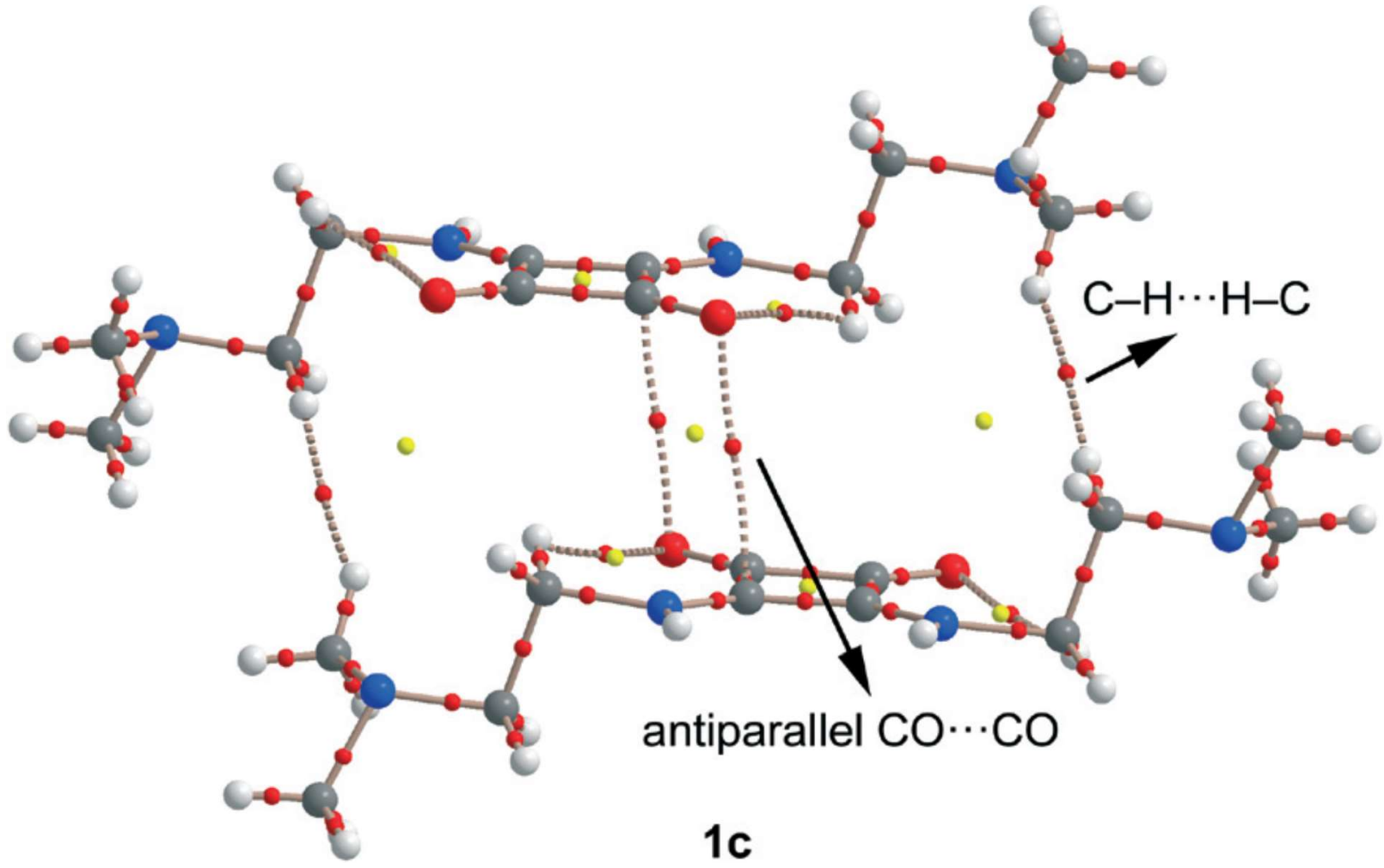




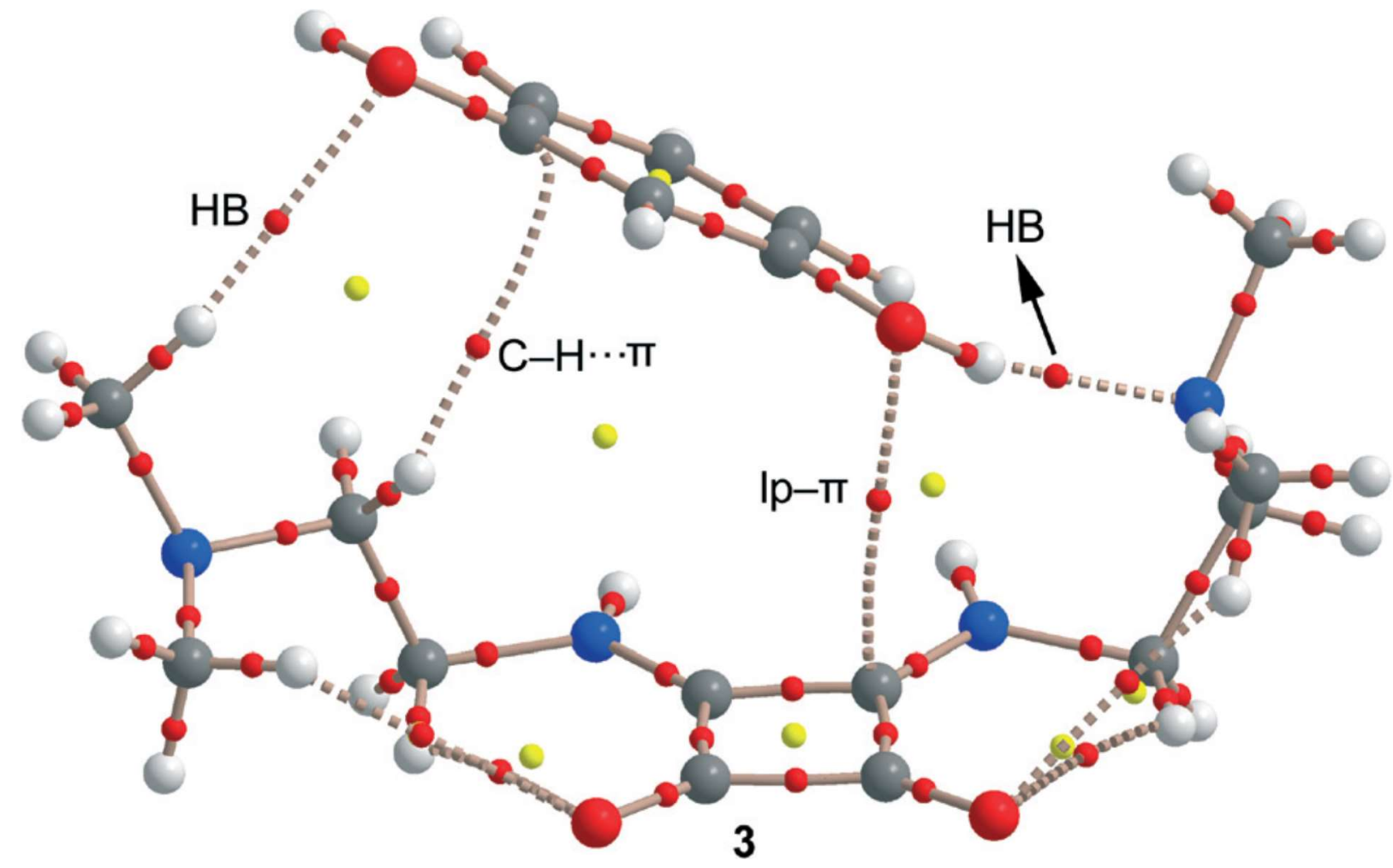


494 Table 1 Crystallographic data and refinement details of compounds 1-3

495

\begin{tabular}{|c|c|c|c|c|}
\hline Structure & 1a & $\mathbf{l b}$ & $1 \mathrm{c}$ & 2 \\
\hline Empirical formula & $\mathrm{C}_{12} \mathrm{H}_{22} \mathrm{~N}_{4} \mathrm{O}_{2}$ & $\mathrm{C}_{12} \mathrm{H}_{22} \mathrm{~N}_{4} \mathrm{O}_{2}$ & $\mathrm{C}_{12} \mathrm{H}_{22} \mathrm{~N}_{4} \mathrm{O}_{2}$ & $\mathrm{C}_{12} \mathrm{H}_{22} \mathrm{~N}_{4} \mathrm{O}_{2}, \mathrm{C}_{6} \mathrm{H}_{6} \mathrm{O}_{2}$ \\
\hline Formula weight & 25.34 & 254.34 & 254.34 & 364.00 \\
\hline Temperature (K) & $293(2)$ & $100(2)$ & 333 & 293 \\
\hline Wavelength (A) & 0.71073 & 0.71073 & 1.54180 & 1.54190 \\
\hline Crystal system & Orthorhombic & Monoclinic & Monoclinic & Tetragonal \\
\hline Space group & Fdd2 & $P 21 / c$ & $C 2, k$ & P42/n \\
\hline \multirow[t]{3}{*}{$a, b, c(\dot{A})$} & $16.185(14)$ & $6.0552(3)$ & $29.6240(17)$ & $25.43120(12)$ \\
\hline & $29.012(18)$ & $14.4565(8)$ & 6.0611 $1(2)$ & $25.43120(12)$ \\
\hline & 6.093(4) & $15.8765(9)$ & 8. $6488(3)$ & $6.06772(3)$ \\
\hline$\alpha, \beta, \gamma\left({ }^{\circ}\right)$ & $90,90,90$ & $90,97.773(2), 90$ & $90.0,101.974(4), 90.0$ & $90,90,90$ \\
\hline Volume $\left(A^{a}\right)$ & $2861(4)$ & $1377.01(13)$ & $1519.14(12)$ & $3924.27(3)$ \\
\hline$z$ & 8 & 4 & 4 & 8 \\
\hline$\delta(\mathrm{calc})\left(\mathrm{Mg} \mathrm{m}^{-2}\right)$ & 1.181 & 1.227 & 1.112 & 1.234 \\
\hline Absorption coefficient $\left(\mathrm{mm}^{-1}\right)$ & a. 083 & 0.086 & 0.630 & 0.723 \\
\hline$F(000)$ & 1104 & 552 & 552 & 1568 \\
\hline 8 range for data collection ( ${ }^{\circ}$ ) & 2. 81 to 32.42 & 2.590 to 29.645 & $\begin{array}{l}\text { 2. } 031-69.982, \\
\text { step } 0.013(29)\end{array}$ & $\begin{array}{l}2.030-70.007 \\
\text { step } 0.013(29)\end{array}$ \\
\hline Reflections collected/unique & $5245 / 1961$ & $43180 / 3866$ & 662 & 849 \\
\hline Data/restraints/parameters & $1961 / 4 / 85$ & $3866 / 0 / 167$ & $5075 / 28 / 38$ & $2060 / 146 / 126$ \\
\hline Goodness of fit on $F^{2}$ & 1.137 & 1.076 & & \\
\hline Final $R$ indices $[I>2 \sigma(l)]$ & $R_{1}=0.0695, w R_{2}=0.1901$ & $R_{1}=0.0445, w R_{2}=0.1136$ & & \\
\hline$R$ indices (all data) & $R_{1}=0.0950, w R_{2}=0.2027$ & $R_{1}=0.0531, w R_{2}=0.1215$ & $\begin{array}{l}R_{\text {wP }}=0.102 \\
R_{\mathrm{R}}=0.039\end{array}$ & $\begin{array}{l}R_{\mathrm{wP}_{1}}=8.530 \\
\mathrm{CHL}=9.521\end{array}$ \\
\hline Largest diff. peak and hole (e $\left.\dot{A}^{-x}\right)$ & 0.299 and -0.163 & 0.468 and -0.343 & & \\
\hline $\operatorname{CCDC}$ & 1015652 & 1584388 & 1584438 & 1022284 \\
\hline
\end{tabular}


498 Table 2 Calorimetric data for the crystal forms of 1

\begin{tabular}{llllll}
\hline & \multicolumn{2}{l}{ Solid state transition } & & \multicolumn{2}{l}{ Melting } \\
\cline { 2 - 3 } \cline { 5 - 6 } Form & Onset $\left({ }^{\circ} \mathrm{C}\right)$ & $\Delta H\left(\mathrm{Jg}^{-1}\right)$ & & Onset $\left({ }^{\circ} \mathrm{C}\right)$ & $\Delta H\left(\mathrm{Jg}^{-5}\right)$ \\
\hline 1a & 44 & 3 & - & - \\
1b & 128 & 20 & - & - \\
1c & - & - & 227 & 137 \\
1d & 45 & 4 & - & -
\end{tabular}

500 